\title{
Age and sex distribution of Mycobacterium tuberculosis infection and rifampicin resistance in Myanmar as detected by Xpert MTB/RIF
}

\author{
Marva Seifert ${ }^{1 * \dagger}$, Hlaing Thazin Aung ${ }^{2+}$, Nicole Besler ${ }^{1}$, Victoria Harris ${ }^{3}$, Tin Tin Mar ${ }^{4}$, Rebecca E. Colman ${ }^{1}$, \\ Timothy C. Rodwell ${ }^{1}$ and Si Thu Aung ${ }^{4}$
}

\begin{abstract}
Background: Detection of tuberculosis disease (TB) and timely identification of Mycobacterium tuberculosis (Mtb) strains that are resistant to treatment are key to halting tuberculosis transmission, improving treatment outcomes, and reducing mortality.

Methods: We used 332,657 Xpert MTB/RIF assay results, captured as part of the Myanmar Data Utilization Project, to characterize Mtb test positivity and rifampicin resistance by both age and sex, and to evaluate risk factors associated with rifampicin resistance.

Results: Overall, $70 \%$ of individuals diagnosed with TB were males. Test positivity was higher among males (47\%) compared to females (39\%). The highest positivity by age occurred among individuals aged 16-20, with test positivity for females (65\%) higher than for males (57\%). Although a greater absolute number of males were rifampicin resistant, a greater proportion of females (11.4\%) were rifampicin resistant as compared to males (9.3\%). In the multivariate model, history of previous treatment, age less than 30, testing in the Yangon region, and female sex were significantly positively associated with rifampicin resistance after adjusting for HIV status and year test was performed.
\end{abstract}

Conclusions: Our results indicate that young adults were more likely to test positive for TB and be identified as rifampicin resistant compared to older adults.

Keywords: Myanmar, Mycobacterium tuberculosis, Rifampicin resistance, Xpert MTB/RIF, Sex, Age

\section{Background}

Tuberculosis (TB) disease remains the leading cause of death from a single infectious agent globally, and although the number of underreported and underdiagnosed cases continues to trend downward, the gap between incident cases and reported cases in 2019 was estimated to be approximately three million worldwide [1]. This gap in

\footnotetext{
* Correspondence: mseifert@ucsd.edu

${ }^{+}$Marva Seifert and Hlaing Thazin Aung contributed equally to this work. 'University of California San Diego, 9500 Gilman Dr, La Jolla, CA 92093, USA

Full list of author information is available at the end of the article
}

disease detection not only contributes to ongoing transmission, but also reduces the probability of treatment success, particularly for individuals infected with strains of Mycobacterium tuberculosis (Mtb) that are drug resistant. In 2018 the World Health Organization (WHO) estimated that only one in three individuals resistant to rifampicin and isoniazid, known as multi-drug resistant TB (MDRTB), were enrolled in appropriate treatment $[1,2]$, due to the lack of accurate and timely diagnostic solutions for drug resistance detection. The recent introduction of

(c) The Author(s). 2021 Open Access This article is licensed under a Creative Commons Attribution 4.0 International License, which permits use, sharing, adaptation, distribution and reproduction in any medium or format, as long as you give appropriate credit to the original author(s) and the source, provide a link to the Creative Commons licence, and indicate if changes were made. The images or other third party material in this article are included in the article's Creative Commons licence, unless indicated otherwise in a credit line to the material. If material is not included in the article's Creative Commons licence and your intended use is not permitted by statutory regulation or exceeds the permitted use, you will need to obtain permission directly from the copyright holder. To view a copy of this licence, visit http://creativecommons.org/licenses/by/4.0/ The Creative Commons Public Domain Dedication waiver (http://creativecommons.org/publicdomain/zero/1.0/) applies to the data made available in this article, unless otherwise stated in a credit line to the data. 
rapid molecular based methods that simultaneously detect the presence of $M t b$ and rifampicin resistance has provided an opportunity to reduce this diagnostic gap. Understanding factors associated with missed cases and identifying sub-populations at increased risk for drug resistance will allow for more efficient utilization of limited programmatic resources.

Globally, TB incidence is significantly higher in males compared to females, and in 2018, the WHO reported that that $56 \%$ of the global TB burden was among adult males, $32 \%$ among adult females, and 12\% among children $[1,3]$. Although country-specific variation in sex distribution of incident TB has been identified [4], incomplete age disaggregation of TB surveillance data has complicated disease burden estimates for young adults and has hampered our understanding of risk of both TB disease and drug resistance among these age groups [5]. Additionally, previous treatment for TB has emerged as the most significant predictor of MDR-TB worldwide, however a growing proportion of individuals without a history of previous treatment are being diagnosed with MDR-TB, indicating the need for more resistance testing in groups not traditionally at risk of drug resistance [69]. There is less consensus regarding other risk factors associated with resistant disease, and while multiple studies indicate that female sex $[7,8,10]$ and younger age $[6,7,11]$ are associated with increased risk of MDR$\mathrm{TB}$, other studies demonstrate that older age [12] and male sex $[13,14]$ are associated with increased risk of resistance. This lack of granular country-level data of both age and sex distribution of disease continues to hamper programmatic targeting for both $M t b$ case finding and resistance detection.

While the WHO has ranked Myanmar in the top 14 countries impacted by a trifecta of increased risk: high burden of TB disease, HIV/TB coinfection, and multidrug resistant $\mathrm{TB}$; national $\mathrm{TB}$ prevalence surveys in Myanmar have shown significant reductions in TB incidence over the last decade [1]. Recent scale up of incountry rapid testing capacity using a national network of Xpert MTB/RIF (Cepheid, Sunnyvale, CA, USA) linked to the Myanmar Data Utilization Project has further increased testing capacity and diagnosis of TB and MDR-TB. This expansion of national rapid diagnostic capability and connectivity provides a unique opportunity to explore the characteristics of TB disease by both age and sex, and to identify at-risk sub-populations for additional diagnostic targeting [15-18]. The primary aim of this study was to utilize the electronically captured data to uncover demographic risk factors and patterns associated with TB diagnosis and rifampicin resistance specific to Myanmar. A secondary aim was to use Xpert $\mathrm{MTB} / \mathrm{RIF}$ results to identify regions of the $r p o B$ gene most frequently associated with rifampicin resistance circulating in Myanmar. This analysis of country-wide TB diagnostic data is the first study in Myanmar to rely on Xpert MTB/RIF results to characterize the epidemic on a national level and can be used to inform programmatic strategies to continue to identify and effectively close country-specific diagnostic gaps.

\section{Methods}

\section{Study data}

Xpert MTB/RIF data on $M t b$ detection and drug resistance, together with associated demographic data, were captured as part of the Myanmar Data Utilization and Connectivity Project for the period from January 2015 to December 2018 and used for analysis. Demographic data were entered electronically at GeneXpert deployment sites, and Xpert MTB/RIF results were automatically generated and collated centrally using the GxAlert connectivity solution from SystemOne (Northhampton, MA, USA), as part of the national testing effort. While the algorithms for determining which individuals received Xpert testing evolved over the project period as part of the continued rollout of Xpert MTB/RIF testing in Myanmar, initial inclusion criteria in 2015 for testing in all regions except for Yangon, included all individuals with a history of TB treatment, all HIV positive TB cases, and all MDR-TB contacts. Within Yangon, in addition to previously listed inclusion criteria, all smear positive individuals were also tested using Xpert MTB/RIF. In May of 2015 inclusion criteria expanded for all regions to include individuals with positive smears at two months post-treatment initiation, children under 15 who were able to produce sputum, children under 15 at risk of TB meningitis, all smear negative patients with abnormal radiographic findings, individuals at risk of having drug resistant $\mathrm{TB}$, individuals living with HIV, individuals with diabetes, and persons with a history of TB treatment.

Data were stripped of unique patient identifiers prior to analysis and records missing sex data were excluded. Records containing missing age variables, reported as 99 (coded as missing data), or listed ages of 100 or greater were removed. Age was collapsed into five-year increments, with the exception of individuals ages 80 to 98 which were aggregated into a single age category. The final dataset included test records from 87 deployment facilities across Myanmar and included the following variables: test date, Xpert MTB/RIF assay result (including both $M t b$ and rifampicin resistance detection and the corresponding resistance probe(s)), sex, age category, HIV status, and self-reported history of previous treatment.

\section{Mtb detection and rifampicin resistance determination}

The molecular beacon technology used by the Xpert $\mathrm{MTB} / \mathrm{RIF}$ assay detects mutations on the rpoB gene 
which are associated with phenotypic rifampicin resistance $[2,19]$. Five overlapping probes span the 81 base pair resistance determining region (codons 507-533 in the E.coli system or 426-452 in the Mtb system) of the gene and are designed to hybridize, or bind, to wildtype deoxyribonucleic acid (DNA). When a probe binds to the wildtype DNA target, the beacon undergoes a conformational change and fluoresces. If two or more of the five beacon probes hybridize and fluoresce, the results are classified as positive and indicate the detection of $M t b$ DNA. Mutations within the target sequence interfere with hybridization of the probe and result in partial or total suppression of the fluorescence of a probe. If one or more of the beacon probes fail to fluoresce the result is classified as rifampicin resistant and the nonfluorescing probe or probes are identified as regions containing resistance conferring mutations [20].

\section{Statistical analysis}

We modeled the proportion of patients by both age category and sex, who tested positive for $M t b$ out of all Xpert MTB/RIF assay results recorded each year, to detect temporal patterns in $M t b$ positivity. Differences in the proportion of $M t b$ positive individuals who were identified as rifampicin resistant were also stratified by both sex and age category to identify higher risk individuals. Additionally, prevalence of specific mutation probes used for resistance determination were assessed both by sex and age category. All study variables potentially associated with rifampicin resistance were initially evaluated using univariate analysis to determine association with rifampicin resistance and then were included in a multivariate logistic regression model to determine association with rifampicin resistance in context of other covariates. Odds ratios and 95\% confidence intervals were calculated as measures of association, and $P<0.05$ was considered statistically significant. All analyses were performed using STATA/SE 15.1 (Stata Corp, College Station, TX, USA).

\section{Ethics}

The need for informed consent was waived and the study was approved as conducted by the Ethics Review Committee, Department of Medical Research, Ministry of Health and Sports, the Republic of the Union of Myanmar (Approval number - Ethics/DMR/2018/155). All analyses were performed in accordance with guidelines and regulations for working with de-identified data. In addition, ethics approval was sought from the University of California San Diego Institutional Review Board, La Jolla, CA, USA, however the study was determined to be exempt from review.

\section{Results}

A total of 339,358 Xpert MTB/RIF results were captured between 2015 and 2018 as part of the Myanmar Data Connectivity Project. Five-thousand, eight-hundred and fourteen (5814) records with patient age missing or recorded as greater than 99 , and 886 records with missing or unidentified patient sex, were excluded from the dataset, resulting in a total of 332,657 (98\%) records used for analysis. Because data were captured as deployment sites were being added to the project, the number of individuals tested each year using Xpert MTB/RIF tripled during the course of the project, increasing from 42,327 in 2015 to 122,724 in 2018. Forty-four percent (44\%) of all Xpert MT/RIF results were positive for $M t b$ and only $5 \%$ were invalid, had an error, or gave no result (see Table 1). Of the 147,328 Mtb positive results, $10 \%(14,660)$ were rifampicin resistant. Approximately $18 \%$ of all individuals tested had a record of being HIV positive and 36\% reported previous treatment for TB.

A vast majority (70\%) of all Xpert MTB/RIF positive individuals were male. $M t b$ test positivity varied significantly by sex; overall $39 \%$ of all females tested were $M t b$ positive compared to $47 \%$ of all males tested (Pearson chi2 $=147.6$, $\mathrm{p}$ value $<0.001)$. Although the total number of assays administered increased each year, the proportion that were $M t b$ positive for each age category

Table 1 Characteristics of the study population stratified by sex

\begin{tabular}{|c|c|c|}
\hline & \multicolumn{2}{|l|}{ Sex } \\
\hline & $\begin{array}{l}\text { Males } \\
(n=218,963)\end{array}$ & $\begin{array}{l}\text { Females } \\
(n=113,694)\end{array}$ \\
\hline Mtb Positive Result (\%) & $103,008(47.0)$ & $44,320(39.0)$ \\
\hline Rifampicin Resistant & 9604 & 5056 \\
\hline Invalid/Error/No result (\%) & $11,268(5.1)$ & $6010(5.3)$ \\
\hline \multicolumn{3}{|l|}{ HIV Status } \\
\hline Negative (\%) & $90,292(41.2)$ & $44,673(39.3)$ \\
\hline Unknown (\%) & $89,321(40.8)$ & $49,855(43.9)$ \\
\hline Positive (\%) & $39,350(18.0)$ & $19,166(16.9)$ \\
\hline \multicolumn{3}{|l|}{ Treatment History } \\
\hline None (\%) & $131,861(60.2)$ & $73,266(63.6)$ \\
\hline Unknown (\%) & $6182(2.8)$ & $3357(3.0)$ \\
\hline Yes (\%) & $80,920(37.0)$ & $38,071(33.5)$ \\
\hline \multicolumn{3}{|l|}{ Region } \\
\hline Yangon (\%) & $81,828(37.4)$ & $45,791(40.3)$ \\
\hline All other regions combined (\%) & $137,135(62.6)$ & $67,903(59.7)$ \\
\hline \multicolumn{3}{|l|}{ Test Year } \\
\hline 2015 & 28,008 & 14,319 \\
\hline 2016 & 45,548 & 23,456 \\
\hline 2017 & 65,064 & 33,538 \\
\hline 2018 & 80,343 & 42,381 \\
\hline
\end{tabular}


remained similar year over year as evidenced in Fig. 1a and Fig. 1b. $M t b$ positive results stratified by year and age category indicate that peak $M t b$ test positivity (57\%) for males occurred between ages 16-20 and Mtb test positivity remained above $50 \%$ until ages $51-55$ (Fig. 1a). $M t b$ positivity in females peaked at $65 \%$ in the same age range of $16-20$, however $M t b$ positivity declined rapidly and fell below $50 \%$ by ages $26-30$ (Fig. 1b). Median age for receiving a Xpert MTB/RIF test for males was 44 (IQR: 32,55) and for females was 41 (IQR: 27, 55) (data not shown). The male to female Xpert MTB/RIF positive ratio was 2.3.

Rifampicin resistance differed both by sex and age. Overall, among females who were positive for $M t b$, $11.4 \%$ were rifampicin resistant and among males, 9.3\% were rifampicin resistant (Pearson chi2 $=147.6288 P$ value $<0.001$ ). Even though the absolute number of rifampicin resistant individuals increased each year during the data collection period, from 2913 in 2015 to 4174 in 2018, the proportion of $M t b$ positive patients identified as being rifampicin resistant declined year over year. For females, detected rifampicin resistance declined from $20.0 \%$ in 2015 to $8.3 \%$ in 2018 , and among males declined from $15.8 \%$ in 2015 to $7.1 \%$ in 2018 .

When stratified by age category, rifampicin resistance was highest among individuals aged 21-25 for both males and females compared to all other age categories. The proportion of rifampicin resistance over the fouryear study period among ages $21-25$ was $15.7 \%$ for females and $13.1 \%$ for males. Eighteen percent of previously treated individuals were identified as rifampicin resistant and $7 \%$ of individuals with no history of previous treatment were resistant.

Individual probe level rifampicin resistance data was available for $85.1 \%(12,481)$ of the reported rifampicin resistant results. Lack of hybridization to one of the five beacon probes (single probe resistance) accounted for
97.2\% $(12,125)$ of all resistance calls. The remaining individual probe level resistance was due to lack of hybridization to two or three of the five beacon probes and accounted for $2.4 \%$ (305) and $0.4 \%$ (51) respectively. There were no significant differences by sex (Pearson chi $2=1.8, p$ value $=0.4$ ) or age category (Person chi $2=$ $30.8, \mathrm{p}$ value $=0.5)$ in the total number of individual probes that failed to hybridize for resistance classification.

For single probe resistance, lack of hybridization to probe E accounted for $75.2 \%$ (9116) of all resistance calls. This failure of probe $\mathrm{E}$ hybridization accounted for $77.9 \%$ of all single probe resistance calls among females and $73.7 \%$ of single probe resistance calls among males. The most common double probe resistance combinations were probes $\mathrm{D}$ and $\mathrm{E}$ and probes $\mathrm{A}$ and $\mathrm{B}$, which accounted for $32.8 \%$ (100) and $25.3 \%$ (77) of double probe resistance calls respectively. Lack of hybridization on three probes, A, B, and E accounted for $51.0 \%$ (26) of all triple probe resistance calls.

Logistic regression was used to determine if sex, age less than 30, previous treatment, test year, Yangon region, and HIV status were associated with rifampicin resistance (see Table 2). In the adjusted model, female sex, age less than 30, Yangon region, and history of previous treatment were all positively and significantly associated with increased risk of rifampicin resistance. Individuals with a history of previous treatment were 2.85 (95\% CI $2.75,2.96)$ times more likely than individuals without a history of treatment to be diagnosed with rifampicin resistance, individuals tested within the Yangon region were $1.92(95 \%$ CI $1.85,1.99)$ times more likely than individuals from all other regions combined to be diagnosed with rifampicin resistance, individuals age 30 and younger were $1.63(95 \% \mathrm{CI} 1.57,1.70)$ times more likely than individuals older than age 30 to be diagnosed with rifampicin resistance, and females were 1.22 (95\%CI
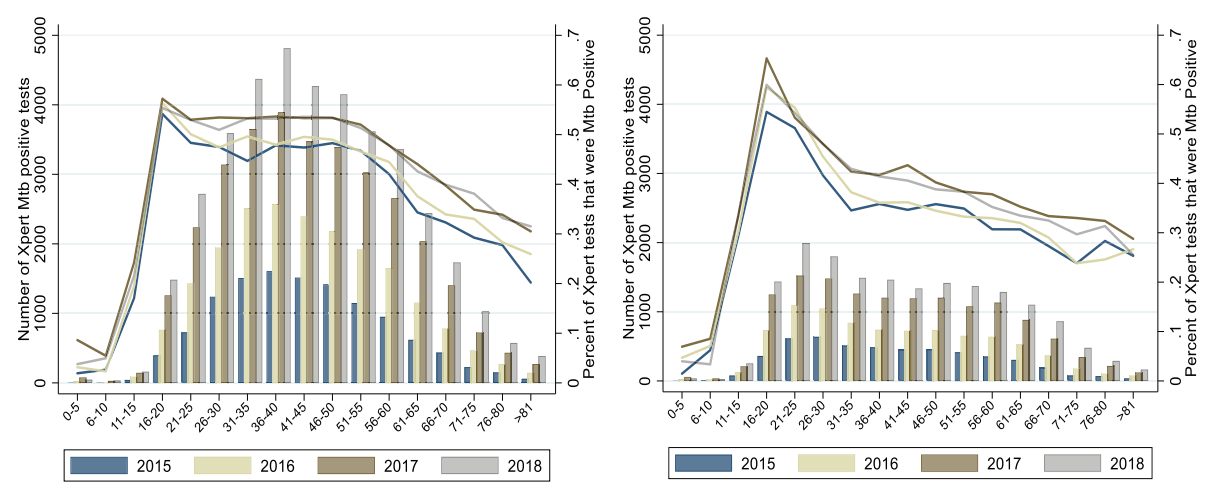

Fig. 1 Mtb positive results stratified by age category for males (a) and females (b). The yearly counts of Mtb positive results for each age category are represented by bars, and the proportion of Mtb positive results to total GeneXpert MTB/RIF results for each age category is represented by lines (second $y$-axis) 
Table 2 Crude and adjusted odds ratios for rifampicin resistance by sex, age, HIV status, history of previous treatment, region, and year of Xpert MTB/RIF assay administration. Total Mtb positive $n=147,327$

\begin{tabular}{|c|c|c|c|c|c|c|}
\hline \multirow{2}{*}{$\begin{array}{l}\text { Demographic } \\
\text { and clinical } \\
\text { characteristics }\end{array}$} & \multicolumn{2}{|c|}{ Rif-Resistant } & \multicolumn{2}{|l|}{ Crude } & \multicolumn{2}{|l|}{ Adjusted } \\
\hline & $n$ & $\%$ & Odds ratio & $95 \% \mathrm{Cl}$ & Odds ratio & $95 \% \mathrm{Cl}$ \\
\hline \multicolumn{7}{|l|}{ Sex } \\
\hline Male & 9604 & 9.3 & reference & & reference & \\
\hline Female & 5056 & 11.4 & 1.25 & $1.21,1.30$ & 1.22 & $1.17,1.26$ \\
\hline \multicolumn{7}{|l|}{ Age } \\
\hline$>30$ years & 9881 & 8.9 & reference & & reference & \\
\hline$<31$ years & 4779 & 13.1 & 1.54 & $1.49,1.60$ & 1.63 & $1.57,1.70$ \\
\hline \multicolumn{7}{|l|}{ HIV status } \\
\hline Negative & 6720 & 9.1 & reference & & reference & \\
\hline Unknown & 6748 & 11.4 & 1.30 & $1.25,1.34$ & 1.01 & $0.97,1.04$ \\
\hline Positive & 1192 & 8.6 & 0.94 & $0.88,1.01$ & 0.87 & $0.82,0.93$ \\
\hline \multicolumn{7}{|c|}{ Previous treatment } \\
\hline None & 7766 & 7.3 & reference & & reference & \\
\hline Unknown & 375 & 9.0 & 1.26 & $1.13,1.40$ & 1.31 & $1.18,1.47$ \\
\hline Yes & 6519 & 17.8 & 2.76 & $2.66,2.86$ & 2.85 & $2.75,2.96$ \\
\hline \multicolumn{7}{|l|}{ Selected Region } \\
\hline Other regions & 6660 & 7.5 & reference & & reference & \\
\hline Yangon & 8000 & 13.7 & 2.0 & $1.89,2.02$ & 1.92 & $1.85,1.99$ \\
\hline \multicolumn{7}{|l|}{ Year of Test } \\
\hline 2015 & 2913 & 17.0 & reference & & reference & \\
\hline 2016 & 3529 & 12.2 & 0.68 & $0.64,0.72$ & 0.79 & $0.75,0.83$ \\
\hline 2017 & 4034 & 8.8 & 0.47 & $0.45,0.50$ & 0.65 & $0.62,0.70$ \\
\hline 2018 & 4174 & 7.5 & 0.40 & $0.38,0.42$ & 0.58 & $0.55,0.61$ \\
\hline
\end{tabular}

$1.17,1.26)$ times more likely than males to be diagnosed with rifampicin resistance after taking into account HIV status and year of assay administration.

\section{Discussion}

This population-based Xpert MTB/RIF analysis followed expected gender distributions [21]; 70\% of individuals diagnosed with $M t b$ were males, and overall, the proportion of males who were $M t b$ positive out of all males tested (47\%) was higher than the proportion of females who were positive for $M t b$ (39\%), replicating previous smaller scale regional reports from Myanmar [15]. Examination by age category revealed that $M t b$ test positivity differed significantly over life course with the highest proportion of individuals who tested positive for $M t b$ among those aged 16-20 (Fig. 1). Prevalence of rifampicin resistance also differed by age and sex, and although a greater absolute number of males were rifampicin resistant over the period analyzed, the proportion of $M t b$ positive individuals identified as rifampicin resistant overall was greater for females as compared to males, $11.4 \%$ versus $9.3 \%$ (Fig. 2). Rifampicin resistance was highest among those who had previously been treated for TB compared to those who had no history of treatment (17.8\% versus $7.3 \%)$; and in the multivariate model in addition to previous treatment, both age less than 30 and female sex were still significantly associated with rifampicin resistance after taking into account HIV status and year test was performed (Table 2). These higher $M t b$ test positivity and resistance rates among young adults provide a potential opportunity to target Xpert MTB/RIF screening among individuals not traditionally classified as high risk [22].

When compared to TB infection models proposed by Seddon et al. and Marais et al., Xpert MTB/RIF results in this population-based cohort exhibited strikingly similar age and sex stratified patterns [23, 24]. Although few children age less than five in our dataset were tested for or diagnosed with pulmonary TB disease when compared to adults, models indicate that this age group is at increased risk of extrapulmonary forms of disease, which would have excluded them from the Myanmar Xpert MTB/RIF testing algorithm. Both absolute numbers of incident cases and $M t b$ test positivity rates were lowest 


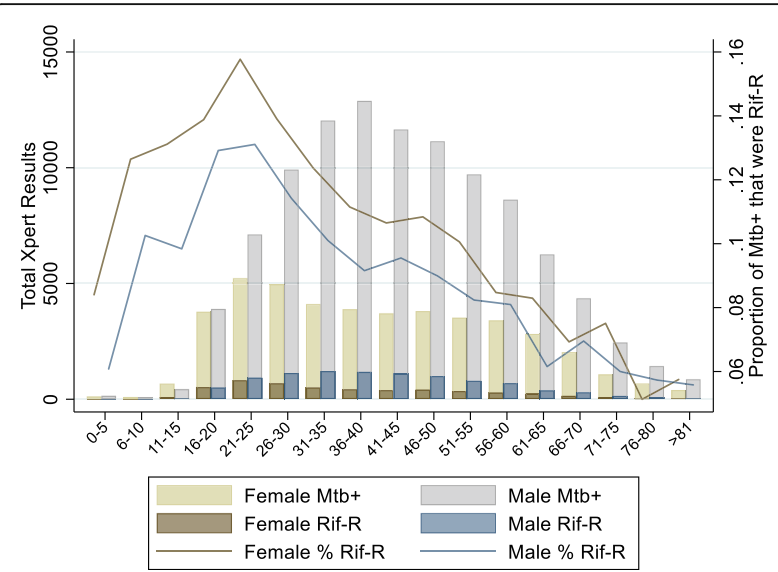

Fig. 2 Mtb positive results and proportion rifampicin resistant by age category and sex. The total number of Xpert Results by age category are represented by the bars, and the proportion of Mtb positive results that were rifampicin positive are represented by lines (second y-axis)

among children aged 5-10 in our dataset, again following proposed models that indicate risk of progression to either pulmonary or extrapulmonary disease falls to its lowest point among this age group. As expected the risk of having pulmonary disease rose dramatically among young adults, likely due to adolescent changes in sex hormone mediated immunological response to infection, increasing their risk of pulmonary disease $[25,26]$. In our dataset females exhibited an earlier rise in $M t b$ test positivity as compared to males, resulting in a larger absolute number of $M t b$ cases among females in the 11-15 age group compared to males (Fig. 1). The proportion of individuals testing positive for $M t b$ was highest for both males and females in the age 16-20 group, however $M t b$ positivity remained above $50 \%$ for males until age $51-$ 55 , in contrast to females where $M t b$ positivity declined dramatically and dropped below $50 \%$ by age $26-30$, resulting in significantly larger number of males being diagnosed with $M t b$ infection. Although young adults are often considered at 'low risk' of TB, our data indicate that additional testing may be warranted in this cohort as their risk of TB and role in transmission may be more substantial than previously understood [27].

Unsurprisingly, over the four-year study period as the number of deployment sites grew and the total number of individuals being tested increased, the total number of individuals identified as being rifampicin resistant year over year increased. However, as the inclusion criteria for Xpert MTB/RIF testing evolved and expanded to include more presumptive $M t b$ positive cases, the proportion of $M t b$ positive patients with rifampicin resistance actually declined for both males and females. Overall, the proportion of rifampicin resistance among $M t b$ positive individuals remained greatest among females compared to males for all age categories (see Fig. 2). The proportion of $M t b$ positive individuals that were identified as rifampicin resistant peaked for both males and females age $21-25$, at 13 and $16 \%$ respectively, which is consistent with other studies identifying increased risk of rifampicin resistance among young adults [7, 13]. Approximately $38 \%$ of all Xpert MTB/RIF testing occurred in the Yangon region, and the proportion of individuals who were rifampicin resistant was significantly higher in this region compared to all other regions combined, $13.7 \%$ versus $7.5 \%$. In the multivariate model (see Table 2 ), history of previous treatment and younger age were the largest risk factors for resistance in the study cohort which has been consistently demonstrated previously $[6$, $8-10,12,28-30]$. Additionally, the increased risk for rifampicin resistance among females identified in our study was consistent with multiple other populationbased studies [7, 8, 10,28], but did conflict with smaller studies that have found male sex associated with an increased risk of resistance [13, 14]. Positive HIV status appeared to be protective in our dataset, however this is likely driven by the selection bias of Xpert MTB/RIF testing criteria during the study period where all HIV positive individuals at risk for $\mathrm{TB}$ were included in the testing algorithm.

Rifampicin resistance was driven primarily by the Xpert MTB/RIF probe $E$ accounting for $75 \%$ of all resistance determinations. Probe E encompasses rpoB codons 528 to 533 , and is likely associated with the rpoB 531 TTG mutation, the most common mutation associated with rifampicin resistance in this genetic region [31, 32]. This is similar to results from a recent studies in Pakistan and Ethiopia where a similar percentage of rifampicin-resistant isolates was associated with mutations on probe $\mathrm{E}[2,33]$. Less than $3 \%$ of resistance determination was caused by multiple probes, slightly higher than the previously reported multiple mutation prevalence detected by Xpert MTB/RIF of approximately $1 \%$ [2].

\section{Limitations}

This dataset included only individuals who met Xpert $\mathrm{MTB} /$ RIF testing criteria and by definition were at increased risk of rifampicin resistance with the exception of individuals living with HIV, and therefore both gender and age distributions do not necessarily represent the entire cohort of individuals who were tested for $\mathrm{TB}$ during the study period and may not accurately represent positivity rates among individuals at risk for $M t b$ in Myanmar. In addition, there was no reference sequencing data to confirm single nucleotide polymorphisms or the accuracy of multiple mutations associated with resistance as detected by the Xpert MTB/RIF assay. 


\section{Conclusions}

Males accounted for the majority of $M t b$ positive cases in Myanmar and are at highest risk for TB disease throughout most of their adulthood, requiring continued focus on testing for this population. In addition, our analyses indicate that targeted testing among both males and females age 16-20 is warranted as our data indicate this age group has the highest proportion of $M t b$ positive results. Further evaluation is needed to identify agespecific barriers to testing that may contribute to these differential positivity rates. Moreover, among $M t b$ positive individuals both males and females less than age 30, and women overall were diagnosed with rifampicin resistance at higher rates than individuals older than age 30 , or men overall. These higher risk sub-populations, males and females less than age 30, and females in all age categories, along with individuals who have been previously treated for $\mathrm{TB}$, should also be targeted for Xpert MTB/RIF testing.

\section{Acknowledgements}

Not applicable.

\section{Authors' contributions}

MS conceptualized the study, curated the data, conducted the formal analysis and data visualizations, and wrote the original draft. HTA collected the data, guided study design and data analysis, and edited the manuscript. NB assisted with data analysis, data visualizations, and manuscript preparation. $\mathrm{VH}$ assisted with data collection and study conceptualization. TTM collected study data. REC assisted with study design and data analysis. TCR assisted with study design and manuscript editing. STA collected data and oversaw study implementation. All authors read and approved the final manuscript.

\section{Funding}

This study was unfunded. MS received support from NIH/National Heart, Lung, and Blood Institute T32HL134632. Data collection was supported in part through a grant from the Bill and Melinda Gates Foundation (OPP1148400)

\section{Availability of data and materials}

The datasets used and/or analyzed during the current study are available from the corresponding and/or senior author on reasonable request.

\section{Declarations}

The need for informed consent was waived and the study was approved as conducted by the Ethics Review Committee, Department of Medical Research, Ministry of Health and Sports, the Republic of the Union of Myanmar (Approval number - Ethics/DMR/2018/155). All analyses were performed in accordance with guidelines and regulations for working with de-identified data. In addition, ethics approval was sought from the University of California San Diego Institutional Review Board, La Jolla, CA, USA, however the study was determined to be exempt from review.

\section{Consent for publication}

Not Applicable.

\section{Competing interests}

The authors declare that they have no competing interests.

\section{Author details}

${ }^{1}$ University of California San Diego, 9500 Gilman Dr, La Jolla, CA 92093, USA. ${ }^{2}$ Clinton Health Access Initiative, Yangon, Myanmar. ${ }^{3}$ FIND, the global alliance for diagnostics, Campus Biotech, 9 Chemin des Mines -, 1202 Geneva,
Switzerland. ${ }^{4}$ Ministry of Health and Sports, Office No. 4, Naypyitaw, Myanmar.

Received: 22 March 2021 Accepted: 31 May 2021

Published online: 09 August 2021

\section{References}

1. World Health Organization: Global tuberculosis report 2020. Geneva, Switzerland. https://www.who.int/publications/i/item/9789240013131.

2. Ullah I, Shah AA, Basit A, Ali M, Khan A, Ullah U, et al. Rifampicin resistance mutations in the $81 \mathrm{bp} \mathrm{RRDR}$ of rpoB gene in mycobacterium tuberculosis clinical isolates using Xpert MTB/RIF in Khyber Pakhtunkhwa, Pakistan: a retrospective study. BMC Infect Dis. 2016;16:413.

3. Horton KC, MacPherson P, Houben RM, White RG, Corbett EL. Sex differences in tuberculosis burden and notifications in low- and middleincome countries: a systematic review and meta-analysis. PLoS Med. 2016; 13(9):e1002119. https://doi.org/10.1371/journal.pmed.1002119.

4. McLaren ZM, Brouwer E, Ederer D, Fischer K, Branson N. Gender patterns of tuberculosis testing and disease in South Africa. Int J Tuberc Lung Dis. 2015 . 19(1):104-10. https://doi.org/10.5588/ijtld.14.0212.

5. Snow KJ, Sismanidis C, Denholm J, Sawyer SM, Graham SM. The incidence of tuberculosis among adolescents and young adults: a global estimate. Eur Respir J. 2018;51(2):1702352. https://doi.org/10.1183/13993003.02352-2017.

6. Asgedom SW, Teweldemedhin M, Gebreyesus H. Prevalence of multidrugresistant tuberculosis and associated factors in Ethiopia: a systematic review. J Pathog. 2018;2018:7104921

7. Al Ammari M, Al Turaiki A, Al Essa M, Kashkary AM, Eltigani SA, Ahmed AE. Drug resistant tuberculosis in Saudi Arabia: an analysis of surveillance data 2014-2015. Antimicrob Resist Infect Control. 2018;7(1):12. Epub 2018/02/02. https://doi.org/10.1186/s13756-018-0306-4.

8. Lomtadze N, Aspindzelashvili R, Janjgava M, Mirtskhulava V, Wright A, Blumberg HM, et al. Prevalence and risk factors for multidrug-resistant tuberculosis in the republic of Georgia: a population-based study. Int J Tuberc Lung Dis. 2009;13(1):68-73.

9. Chen MP, Miramontes R, Kammerer JS. Multidrug-resistant tuberculosis in the United States, 2011-2016: patient characteristics and risk factors. Int J Tuberc Lung Dis. 2020;24(1):92-9. https://doi.org/10.5588/ijtld.19.0173.

10. Liu Q, Zhu L, Shao Y, Song H, Li G, Zhou Y, et al. Rates and risk factors for drug resistance tuberculosis in northeastern China. BMC Public Health. 2013; 13(1):1171. https://doi.org/10.1186/1471-2458-13-1171.

11. Ullah I, Javaid A, Tahir Z, Ullah O, Shah AA, Hasan F, et al. Pattern of drug resistance and risk factors associated with development of drug resistant mycobacterium tuberculosis in Pakistan. PLoS One. 2016;11(1):e0147529. https://doi.org/10.1371/journal.pone.0147529.

12. Pradipta IS, Forsman LD, Bruchfeld J, Hak E, Alffenaar JW. Risk factors of multidrug-resistant tuberculosis: a global systematic review and metaanalysis. J Infect. 2018;77(6):469-78. https://doi.org/10.1016/j.jinf.2018.10.004.

13. Merza MA, Farnia P, Tabarsi P, Khazampour M, Masjedi MR, Velayati AA. Antituberculosis drug resistance and associated risk factors in a tertiary level TB center in Iran: a retrospective analysis. J Infect Dev Ctries. 2011;5(7):511-9. https://doi.org/10.3855/jidc.1259.

14. Ignatyeva O, Balabanova Y, Nikolayevskyy V, Koshkarova E, Radiulyte B, Davidaviciene $E$, et al. Resistance profile and risk factors of drug resistant tuberculosis in the Baltic countries. Tuberculosis (Edinb). 2015;95(5):581-8. https://doi.org/10.1016/j.tube.2015.05.018.

15. Khan MS, Khine TM, Hutchison C, Coker RJ, Hane KM, Innes AL, et al. Are current case-finding methods under-diagnosing tuberculosis among women in Myanmar? An analysis of operational data from Yangon and the nationwide prevalence survey. BMC Infect Dis. 2016;16:110.

16. Htet KKK, Liabsuetrakul T, Thein S, McNeil EB, Chongsuvivatwong V. Improving detection of tuberculosis among household contacts of index tuberculosis patients by an integrated approach in Myanmar: a crosssectional study. BMC Infect Dis. 2018;18(1):660. https://doi.org/10.1186/s12 879-018-3586-7.

17. Oo T, Kyaw KWY, Soe KT, Saw S, Satyanarayana S, Aung ST. Magnitude and reasons for pre-diagnosis attrition among presumptive multi-drug resistant tuberculosis patients in Bago Region, Myanmar: a mixed methods study. Sci Rep. 2019;9(1):7189. https://doi.org/10.1038/s41598-019-43562-3.

18. Htun YM, Khaing TMM, Aung NM, Yin Y, Myint Z, Aung ST, et al. Delay in treatment initiation and treatment outcomes among adult patients with multidrug-resistant tuberculosis at Yangon regional tuberculosis Centre, 
Myanmar: a retrospective study. PLoS One. 2018;13(12):e0209932. https:// doi.org/10.1371/journal.pone.0209932.

19. Cepheid Xpert MTB/RIF assay for detecting Mycobacterium tuberculosis. MMWR Morb Mortal Wkly Rep. 2015;64(07);193. https://www.cdc.gov/ $\mathrm{mmwr} /$ preview/mmwrhtml/mm6407a8.htm.

20. Lawn SD, Nicol MP. Xpert(R) MTB/RIF assay: development, evaluation and implementation of a new rapid molecular diagnostic for tuberculosis and rifampicin resistance. Future Microbiol. 2011;6(9):1067-82. https://doi.org/1 $0.2217 / \mathrm{fmb} .11 .84$.

21. World Health Organization: Gender and Tuberculosis. Geneva: World Health Organization; 2002. https://apps.who.int/iris/bitstream/handle/10665/ 68891/a85584.pdf.

22. Myint $\mathrm{O}$, Saw S, Isaakidis $\mathrm{P}$, Khogali M, Reid A, Hoa NB, et al. Active casefinding for tuberculosis by mobile teams in Myanmar: yield and treatment outcomes. Infect Dis Poverty. 2017;6(1):77. https://doi.org/10.1186/s40249-01 7-0291-5.

23. Seddon JA, Chiang SS, Esmail H, Coussens AK. The wonder years: what can primary school children teach us about immunity to mycobacterium tuberculosis? Front Immunol. 2018;9:2946. https://doi.org/10.3389/fimmu.201 8.02946.

24. Marais BJ, Gie RP, Schaaf HS, Hesseling AC, Obihara CC, Starke JJ, et al. The natural history of childhood intra-thoracic tuberculosis: a critical review of literature from the pre-chemotherapy era. Int J Tuberc Lung Dis. 2004;8(4): 392-402.

25. Zhao Y, Ying H, Demei J, Xie J. Tuberculosis and sexual inequality: the role of sex hormones in immunity. Crit Rev Eukaryot Gene Expr. 2012;22(3):23341. https://doi.org/10.1615/critreveukargeneexpr.v22.13.60.

26. Borgdorff MW, Nagelkerke NJ, Dye C, Nunn P. Gender and tuberculosis: a comparison of prevalence surveys with notification data to explore sex differences in case detection. Int J Tuberc Lung Dis. 2000;4(2):123-32.

27. Snow KJ, Nelson L, Sismanidis C, Sawyer SM, Graham SM. Incidence and prevalence of bacteriologically confirmed pulmonary tuberculosis among adolescents and young adults: a systematic review. Epidemiol Infect. 2018; 146(8):946-53. https://doi.org/10.1017/S0950268818000821.

28. Ejaz M, Siddiqui AR, Rafiq Y, Malik F, Channa A, Mangi R, et al. Prevalence of multi-drug resistant tuberculosis in Karachi, Pakistan: identification of at risk groups. Trans R Soc Trop Med Hyg. 2010;104(8):511-7. https://doi.org/10.101 6/j.trstmh.2010.03.005.

29. Farazi A, Sofian M, Zarrinfar N, Katebi F, Hoseini SD, Keshavarz R. Drug resistance pattern and associated risk factors of tuberculosis patients in the central province of Iran. Caspian J Intern Med. 2013;4(4):785-9.

30. Nair SA, Raizada N, Sachdeva KS, Denkinger C, Schumacher S, Dewan P, et al. Factors associated with tuberculosis and rifampicin-resistant tuberculosis amongst symptomatic patients in India: a retrospective analysis. PLoS One. 2016;11(2):e0150054. https://doi.org/10.1371/journal.pone.0150054.

31. Miotto P, Tessema B, Tagliani E, Chindelevitch L, Starks AM, Emerson C, et al. A standardised method for interpreting the association between mutations and phenotypic drug resistance in Mycobacterium tuberculosis. Eur Respir J. 2017;50(6):1701354. https://doi.org/10.1183/13993003.01354-2017.

32. Jagielski T, Bakula Z, Brzostek A, Minias A, Stachowiak R, Kalita J, et al. Characterization of Mutations Conferring Resistance to Rifampin in Mycobacterium tuberculosis Clinical Strains. Antimicrob Agents Chemother. 2018;62(10):e01093-18. https://doi.org/10.1128/AAC.01093-18.

33. Alemu A, Tadesse M, Seid G, Mollalign H, Eshetu K, Sinshaw W, et al. Does Xpert ${ }^{\circledR}$ MTB/RIF assay give rifampicin resistance results without identified mutation? Review of cases from Addis Ababa, Ethiopia. BMC Infect Dis. 2020;20(1):87. https://doi.org/10.1186/s12879-020-4817-2.

\section{Publisher's Note}

Springer Nature remains neutral with regard to jurisdictional claims in published maps and institutional affiliations.

Ready to submit your research? Choose BMC and benefit from:

- fast, convenient online submission

- thorough peer review by experienced researchers in your field

- rapid publication on acceptance

- support for research data, including large and complex data types

- gold Open Access which fosters wider collaboration and increased citations

- maximum visibility for your research: over $100 \mathrm{M}$ website views per year

At BMC, research is always in progress.

Learn more biomedcentral.com/submissions 